\title{
Oral Health Status and its Impact on Daily Performance in Adult Population with Diabetes
}

\author{
Dr. Jesmin Sultana Lucky1${ }^{*}$, Dr. Kazi Silvia Kabir², Dr. A F M Shahidur Rahman³, Polash Das ${ }^{4}$
}

\section{AFFILIATION:}

1. Dr. Jesmin Sultana Lucky

Assistant Professor (Dental Public Health)

Shaheed Suhrawardy Medical College, Dental Unit

Cell: 01847161640

Email: lucky.dr@gmail.com

2. Dr. Kazi Silvia Kabir

Lecturer (Dental jurist, law and ethics)

Shaheed Suhrawardy Medical College, Dental Unit Cell: 01674784720

Email: isha.silvia@gmail.com

3. Dr. A F M Shahidur Rahman

Associate Professor (Oral and Maxillofacial surgery)

Shaheed Suhrawardy Medical College, Dental Unit Cell: 01819296714

Email: shahidurlimon@gmail.com

4. Polash Das

Dental student, (D-53)- Dhaka Dental College

Cell: 01772189868

Email: polashddc@gmail.com

\section{Article info.}

Received: 25 November 2020

Accepted: 28 December 2020

Volume: Vol-11, Issue-1, April 2021

DOI: https://doi.org/10.3329/updcj.v11i1.53001

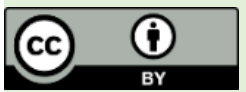

(C) Authors retain copyright and grant the journal right of first publication with the work simultaneously licensed under Creative Commons Attribution License CC - BY 4.0 that allows others to share the work with an acknowledgment of the work's authorship and initial publication in this journal.

https://creativecommons.org/licenses/by/4.0/

Publisher: Update Dental College, Dhaka, Bangladesh

Web: www.updatedentalcollege.edu.bd

E-mail: updcj@hotmail.com

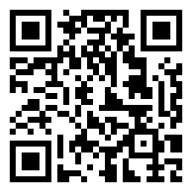

Scan QR code to see the latest issue

* Corresponding Author

Dr. Jesmin Sultana Lucky (BDS, MPH)

Assistant Professor (Dental Public Health)

Shaheed Suhrawardy Medical College Dental Unit

Residence: House 487, Road-16, Block F,

Bashundhara R/A, Dhaka-1229, Bangladesh

Cell: +8801847161640

Email: lucky.dr@gmail.com

\begin{abstract}
:
Background: According to World Health Organization (WHO), diabetes mellitus, is a silent epidemic which affects large number of people around the world and is directly related to the oral health status of the patients.

Objectives: To know the level of oral health and its impact on daily performance in adult population with Diabetes.

Methods: A cross sectional study was comprised of group of 100 diabetic patients (males=68, females=32) from the OPD of Dhaka Dental College and Shaheed Suhrawardy Medical college, Dental unit of Dhaka. Oral health status is assessed by WHO described DMFT caries index and CPITN (community periodontal index treatment need). And oral impact on daily performance is determined by a modified form of OIDP index. Clinical examinations were included for the assessment of Dental Status. Chi-square was used for statistical evaluation.

Results: Mean DMFT of the study population of Decayed, Missing and filled tooth were $3.89 \pm 3.35,3.04 \pm 2.66$ and $3.87 \pm 2.66$ However, in case of CPITN index of the study population, Supragingival or subgingival pocket more than $6 \mathrm{~mm}$ was in $32 \%$ cases. Mean scores of overall impacts on daily performances (OIDP) was $2.18 \pm 1.85$. Bivariate analysis revealed that the self-reported oral impacts from the participants were not significantly associated $(p \geq 0.05)$ with those who were diagnosed with presence of periodontal pockets more than 6 $\mathrm{mm}(32 \%)$.

Conclusions: Oral health is an essential part of general health. Despite dental caries was comparatively low in diabetics, periodontal status was compromised which affected the participant's daily life chiefly through difficulty in eating. Routinely follow-up of dental problems of the diabetics and oral health education is much required.
\end{abstract}

KEYWORDS: Dental caries, diabetes, Community Periodontal Index, Dental Status

\section{INTRODUCTION:}

It is globally recognized that people living with a disability in developing countries are among the poorest, weakest and most vulnerable. It is estimated that $10 \%$ of the world's population, approximately 650 million people, have a disability and those $80 \%$ of the population with a disability live in developing countries [1]. Nowa-days, oral health is understood as a definition which is comfortable, valuable and functional with such an appearance that allows people to perform their social function and daily activities without physical, psychological or social inconvenience [3]. Peterson (2003) suggested of 3 aspects for better oral health promotion, which are 1) oral health is the most composition of general health 2 ) oral health was related in general health and 3) oral health is the most important indicator of quality of life [3]. However, they can affect the ability to take food, speak and socialize without active oral problems and contribute to ones' general well-being [4]. Regrettably, it is nonexistent in many developing countries, where high prevalence of preventable oral diseases exists; with dental caries as the leading cause of tooth loss and over $70 \%$ require periodontal treatment [5]. According to the WHO, at least 220 million people or $2.8 \%$ of the population worldwide suffer from diabetes. Its incidence is increasing rapidly and is estimated that by the year 2030, this number will almost double. The greatest increase in prevalence is expected to be occurred in Asia and Africa. The increase in incidence of diabetes in developing countries follows the trend of urbanization and lifestyle changes [6]. 
Quantifying the prevalence of diabetes and the number of people affected by diabetes, now and in the future, is important to allow rational planning of allocation of resources [7]. Unfortunately, caring for the oral cavity is often overlooked and neglected when trying to control other problems associated with diabetes which may contribute to hidden morbidity and undue suffering from oral health problems [6]. Hence, the study was an attempt to know the oral health status and treatment needs in diabetics and to create awareness of oral health problems among general practitioners.

\section{METHODOLOGY:}

A cross-sectional study was conducted among the Diabetic patients attending out-patients departments of Dhaka Dental College and Hospital (DDCH) and Shaheed Suhrawardy Medical college(ShSMC), Dental Unit of Dhaka city from June 2019 to December 2019 to assess the impact of oral health on their routine life. The procedures followed were in accordance with the ethical standards of the responsible committee on human experimentation (institutional or regional) and with the Helsinki Declaration of 1975, as revised in 2000. Approximately 100 adults (among them 70 from $\mathrm{DDCH}$ and 30 from ShSMC) with Diabetes (30years and over) were included. The project was explained in Bengali to those who showed an interest in the study and if they agreed verbally to take part they were included. A fourth year dental student from DDCH, assisted with the study. Support was provided by Dental students whose placement were in Periodontology Department.

The oral examination was carried out by the dentists and dental students. Duplicate clinical examinations were carried out on a randomly selected sub-sample, considered to be representative of the study subjects, in order to assess reliability. Caries experience was assessed in accordance with the criteria described by the WHO and recorded as DMFT (World Health Organization,1997). A cheek list was prepared to generate the index. Periodontal status was assessed by WHO described CPITN index (Community Periodontal Index Treatment Needs). The examination was done using artificial light with a mouth mirror and CPITN (Community Periodontal Index Treatment Needs) probe. Information about diabetes was taken by a self-administered questionnaire containing level of diabetes, duration of diabetes, whether he is taking oral medicine or insulin.

To assess the Oral Impact on Daily Performance (OIDP) a modified form of the OIDP Inventory translated into Bengali was used. A study conducted in Bangladesh in which Impact on Daily Performance related to wearing orthodontic appliances was done by using the OIDP scale [8]. This is an eight item index referring to the ability to carry out eight daily life activities including eating, talking, cleaning teeth, sleeping, smiling, emotional state, working, socializing. For each activity, there is a score for frequency and Severity. The OIDP score calculation is based on the calculation of Performance scores for each of the performances included in the index (eating, speaking, sleeping etc). The Performance score is equal to the frequency score multiplied by the severity score. The frequency score is expressed on a scale of 0-5 and the severity score on a scale of 0-3, therefore each performance score ranges from 0-15. The overall ODIP score for each person is calculated as the sum of the performance score divided by the maximum total score multiplied by 100 . The higher the score the greater the impact.

8| P a g e
RESULT

The current study was conducted on 100 Diabetic patients, among which 68 (68.0\%) were males and 32 (32\%) were females. Mean age of the participants was $48.5 \pm 11.14$ years. Mean DMFT of the study population of Decayed, Missing and filled tooth were 3.89 \pm 3.35 , $3.04 \pm 2.66$ and $3.87 \pm 2.66$.

In case of CPITN index of the study population, Bleeding on probing was present in case of $26 \%$ respondents (Fig 1), Supragingival or subgingival pocket $1-3 \mathrm{~mm}$ was present in case of $27 \%$ cases, Supragingival or Subgingival pocket $4-5 \mathrm{~mm}$ was in $15 \%$ cases and Supragingival or subgingival pocket more than $6 \mathrm{~mm}$ was in $32 \%$ cases.

Fig 1: CPITN score of the respondents

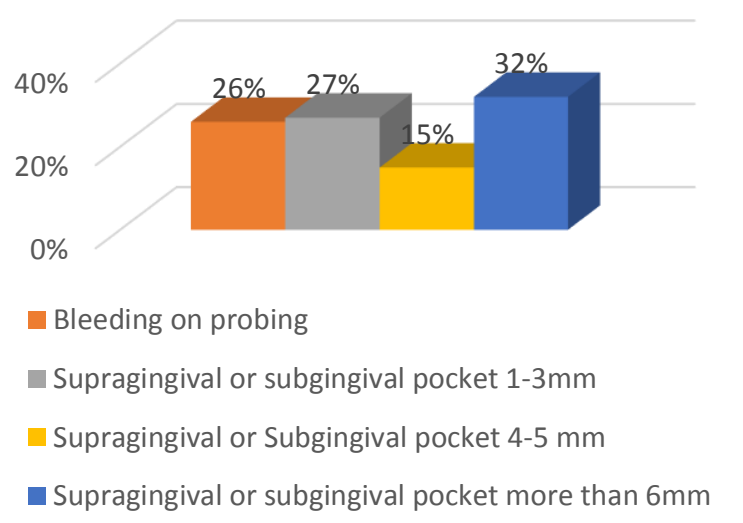

Among all the respondents the CPITN index score 4 (Supragingival or subgingival pocket more than $6 \mathrm{~mm}$ ) percentage was more than any other score (score 1-3). (fig-2)

Fig 2: CPITN score of the respondent of grade (1-3) and grade 4

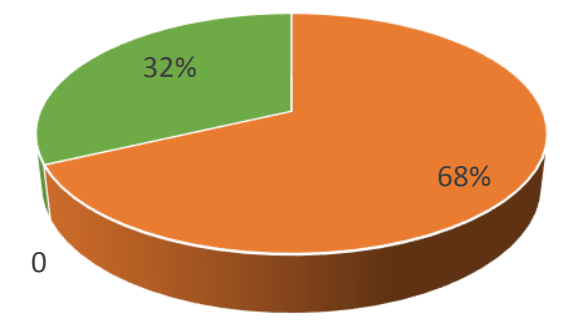

- CPITN score 1-3 - - " CPITN score 4

Mean scores of overall impacts on daily performances (OIDP) was $2.18 \pm 1.85$. Difficulty in talking was the highest $(12 \%)$ reported impact and the lowest (1\%) respondents were towards difficulty in working. [Fig-3] represents the distribution of study subjects according to prevalence of OIDP. Thirty two participants (32\%) reported only one impact affecting their daily living as against 68 participants (68\%) reported more than one impact. The items most commonly affected by oral health status were talking (12\%) and eating food (10\%) followed with cleaning teeth (5\%). Similarly, the least commonly affected were smiling ( $2 \%$ ) with people and working any work (1\%).No

Website: https://www.banglajol.info/index.php/UpDCJ 
respondent showed any response towards oral health status in case of sleeping. [Fig-3] shows the oral conditions perceived by the subjects and the frequency of each that causes impacts on the eight activities.

Fig 3: Distribution of problems which patients felt for his oral condition in OIDP scale

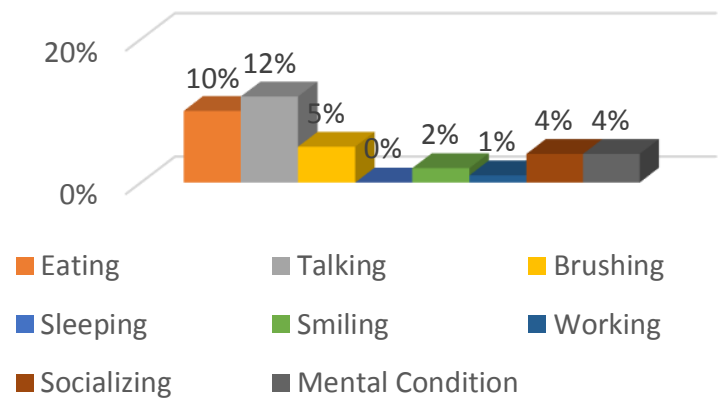

Bivariate analysis [Table-1] revealed that the self-reported oral impacts from the participants were not significantly associated $(p \geq 0.05)$ with those who were diagnosed with presence of periodontal pockets more than $6 \mathrm{~mm}(32 \%)$.

Table-1: Bivariate analysis between OIDP scale and CPITN index

\begin{tabular}{|c|c|c|c|c|c|}
\hline \multirow[t]{2}{*}{ OIDP } & & CPITN & \multirow{2}{*}{$\begin{array}{l}\text { Chi- } \\
\text { square } \\
\text { value }\end{array}$} & \multirow{2}{*}{$\begin{array}{l}\mathbf{P} \\
\text { Value }\end{array}$} & \multirow[t]{2}{*}{ df } \\
\hline & $\begin{array}{l}\text { Score 1- } \\
\text { 3(Bleeding on } \\
\text { probing, ), } \\
\text { Supragingival or } \\
\text { subgingival } \\
\text { pocket 1-3mm } \\
\text { and } 4-5 \mathrm{~mm} \text { ) }\end{array}$ & $\begin{array}{l}\text { Score } \\
4 \text { (Supragingival } \\
\text { or subgingival } \\
\text { pocket more } \\
\text { than } 6 \mathrm{~mm} \text { ) }\end{array}$ & & & \\
\hline $\begin{array}{l}\text { At least } \\
\text { one } \\
\text { Oral } \\
\text { impact }\end{array}$ & $43(43 \%)$ & $25(25 \%)$ & 2.217 & .136 & 1 \\
\hline $\begin{array}{l}\text { More } \\
\text { than } \\
\text { one } \\
\text { Oral } \\
\text { impact }\end{array}$ & $25(25 \%)$ & $7(7 \%)$ & & & \\
\hline
\end{tabular}

\section{DISCUSSION}

The World Health Organization (WHO) Policy Basis on Oral Health places great emphasis on the interaction between oral health and quality of life, [1]. The current study was conducted on 100 Diabetic patients, among which 68 (68.0\%) were males and 32 (32\%) were females. Mean age of the participants was $48.5 \pm 11.14$. Other study was conducted on 414 school teachers, among which 158 (38.2\%) were males and 256 (61.8\%) were females. Mean age of the participants was $40.5 \pm 11.14$ years [4].

In our study, prevalence of dental caries was found to be comparatively lower in diabetics. Mean DMFT of the study population of Decayed, Missing and filled tooth were 3.89 $\pm 3.35,3.04 \pm 2.66$ and $3.87 \pm 2.66$. Similar results are reported by Bacic et al [9], who did a

9 | P a g e study on the oral health status of a group of adult diabetic patients. The reason may be the diet of diabetics, which consists of high protein content and limited fermentable carbohydrates as compared to the diet of non-diabetics, making the diabetics less prone to dental caries.

In the present study, prevalence of periodontal diseases was more in diabetics. Among all the respondents the CPITN index score 4 (Supragingival or subgingival pocket more than $6 \mathrm{~mm}$ ) percentage was more than Bleeding on probing (score 1 ), Supragingival or subgingival pocket 1-3m (score 2), Supragingival or Subgingival pocket 4-5 mm (score 3).Similar results were reported by Matu et al in 2009 [10], in his study of periodontal diseases among diabetic patients in South Africa. Glickmann in 1862 described the oral symptoms of diabetes mellitus as a systemic promoting factor creating suitable conditions producing gingivitis and periodontitis [11]. Epidemiological research indicates that diabetes increases the risk of periodontal diseases. The prevalence of at least one missing tooth was higher in diabetics compared to non-diabetics. This may be due to the progression of gum recession which causes alveolar bone resorption and makes the tooth mobile [6].

The prevalence of oral impacts in the study group was high at the present study. This equates to that reported by Wilson K E et al [1] amongst an adult rural leprosy population in Tanzania where the prevalence was found to be $72.7 \%$ [1]. This would suggest that those in developing countries who have poorer access to oral care, may suffer more from oral health-related problems than those in more affluent countries. In the other study, 38.6\% school teachers reported impacts on daily activities [4] Higher prevalence of OIDP have also been observed in this study in which the reason may be attributed to that this study was conducted upon older age group people specifically, who generally have more of oral problems.

In the present study the items most commonly affected daily life by oral health status were talking (12\%) and eating food (10\%) followed with cleaning teeth (5\%). Similarly, the least commonly affected were smiling (2\%) with people and working any work (1\%). No respondent showed any response towards oral health status in case of sleeping. In other study the most prevalent impact noted was on cleaning teeth, with $66.6 \%$ of the study population reporting this as a problem. Eating was found to be the next most prevalent impact with $63.6 \%$ of the study group same as our study. Eating is one of the most basic and essential daily practices, if compromised, this will have an effect on all aspects of daily life and overall general health [1]. Saxena $A$ et al [4] also found that most commonly experienced impact item was difficulty in eating and chewing food about $16.2 \%[4]$. In the present study thirty-two participants (32\%) reported only one impact affecting their daily living as against $68(68 \%)$ reported more than one impact a similar result found in Saxena A et al [4] around two-third of the participants, reported impact only two performances. In the present study Bivariate analysis revealed that the self-reported oral impacts from the participants were not significantly associated $(p \geq 0.05)$ with those who were diagnosed with presence of periodontal pockets more than $6 \mathrm{~mm}(32 \%)$ which was contrast to the study done by Saxena A at el [4] in India as among all the respondents the CPITN index score 4 (Supragingival or subgingival pocket more than $6 \mathrm{~mm}$ ) percentage was only $7 \%$ having more than one impact.

Website: https://www.banglajol.info/index.php/UpDCJ 


\section{CONCLUSION}

The results of the study show the level of dental disease amongst the diabetic patients. The most revealing data supporting the need for oral health care services is that obtained from the OIDP questionnaire which illustrates the impact that dental disease is having on the population surveyed. The pattern and distribution of epidemiological studies similar to our study seek to advocate that strategies need to be planned for the improvement of oral health of the population. CONFLICT OF INTEREST: Author declared no conflict of interest.

\section{REFERENCES:}

1. Wilson KE and Opie R. Oral health status and oral impact on daily performance in an adult population with leprosy living in rural Tanzania. Journal of Disability and Oral Health. 2009;10/3: 124-130

2. Gomes AS, Abegg C and Guimaraes-Fachel JM. Relationship between oral clinical conditions and daily performances. Braz Oral Res. 2009;23(1):76-81. https://doi.org/10.1590/S1806-83242009000100013 PMid:19488476

3. Sombateyotha $\mathrm{K}$ and Mahaweerawat U. Oral Health Status and Oral Impact on Daily Performance in Elderly in Northeastern Region Thailand. European Journal of Sustainable Development. 2017; 6, 2, 240-244 ISSN: 2239-5938. https://doi.org/10.14207/ejsd.2017.v6n2p240

4. Saxena A, Nagarajappa R and Ramesh G. Oral Impact on Daily Performance among School Teachers in Kanpur, India: A Cross-sectional Study. Journal of Clinical and Diagnostic Research. 2018 Nov; Vol-12(11): ZC27-ZC33. https://doi.org/10.7860/JCDR/2018/37063.12286

5. Lawal FB, Taiwo JO and Oke GA. Impact of Oral Health on the Quality of Life of Elementary School Teachers. Ethiop J Health Sci. 2015;25(3):217-24. https://doi.org/10.4314/ejhs.v25i3.4 PMid:26633924 PMCid:PMC4650876

6. Bharateesh JV, Ahmed M and Kokila G. Diabetes and Oral Health: A Case-control study. Int J Prev Med. 2012; 3:806-9.

7. Wild $S$, Roglic $G$, Green A, Sicree R and King $H$. Global prevalence of diabetes: Estimates for 2000 and projections for 2030. Diabetes Care. 2004 May;27(5):104753. doi: 10.2337/diacare.27.5.1047 https://doi.org/10.2337/diacare.27.5.1047 PMid:15111519

8. Moniruzzaman, Hossain MZ, Sultana M and Sheikh MA. The Prevalence, Intensity and Extent of Oral Impacts on Daily Performances among the Patients Wearing Orthodontic Appliances. Bangladesh Journal of Orthodontics and Dentofacial Orthopedics (BJO \& DFO). 2016 Apr; Vol. 6 No. 1\&2:06-12. https://doi.org/10.3329/bjodfo.v6i1.42396

9. Bacic M, Ciglar I, Planack D, Granic M and Sutalo J. Dental status in a group of adult diabetic patient's. Community Dent Oral Epidemiol.1989;17:313-6. https://doi.org/10.1111/j.1600-0528.1989.tb00645.x PMid:2591185

10. Matu NK, Stephan $L$ and Lalloo R. Prevalence and severity of periodontal disease: Type 2 diabetics versus non diabetics. SADJ. 2009; 64:66-8.

11. Fermin AC. Clinical Periodontology. 7th ed. Philadelphia: W.B. Saunders company; 1990. p. 446

\section{To submit your manuscript, Mail us to : updcj@hotmail.com}

To see our latest issue, click the following link https://www.banglajol.info/index.php/UpDCJ 